\title{
PENINGKATAN PENGETAHUAN MENGENAI OSTEOARTHRITIS LUTUT PADA MASYARAKAT DESA BRANTI RAYA LAMPUNG SELATAN
}

\author{
Helmi Ismunandar ${ }^{1}$, Rani Himayani ${ }^{1}$, Rasmi Zakiah Oktarlina ${ }^{1}$ \\ ${ }^{1}$ Fakultas Kedokteran Universitas Lampung \\ dr.helmiismunandar@gmail.com,dr.ranihimayani@gmail.com
}

\begin{abstract}
Abstrak
Latar Belakang: Osteoarthritis (OA) adalah penyakit degeneratif pada sendi yang menyebabkan hilangnya kartilago sendi secara progresif. Osteoarthritis adalah jenis arthritis (peradangan sendi) yang paling sering terjadi. Kondisi ini menyebabkan sendi-sendi terasa sakit, kaku, dan bengkak. Penyakit ini bisa menyerang semua sendi, namun sendi di jari tangan, lutut, pinggul, dan tulang punggung, adalah sendi-sendi yang paling sering terkena. Pertambahan usia adalah salah satu faktor utama terjadinya kondisi ini. Tujuan: Peningkatan pengetahuan dan kesadaran masyarakat mengenai penyakit osteoarthritis pada lutut. Metode: Dilakukan penyuluhan dengan penilaian dilakukan menggunakan pretes dan postes.

Hasil: Kegiatan diikuti oleh 70 orang masyarakat Desa Branti Raya untuk menghadiri penyuluhan. Berdasarkan data hasil pengamatan pre-test, diketahui sekitar $60 \%$ peserta tidak paham mengenai penyakit osteoarthritis dan $40 \%$ telah mengetahui pengetahuan yang cukup mengenai osteoarthritis. Setelah dilakukan kegiatan penyuluhan, nilai hasil pengamatan meningkat. Sebagian besar peserta menjadi paham mengenai osteoarthritis pada lutut. Setelah dilakukan post-test, dari data yang diperoleh semua peserta sudah paham $(100 \%)$ terhadap osteoarthritis lutut. Kesimpulan: ada peningkatan pengetahuan osteoarthritis di masyarakat.
\end{abstract}

Kata Kunci: Osteoarthritis lutut, nyeri sendi, penyakit degeneratif

\section{PENDAHULUAN}

Osteoarthritis adalah peradangan kronis pada sendi akibat kerusakan pada tulang rawan. Osteoarthritis adalah jenis arthritis (peradangan sendi) yang paling sering terjadi. Kondisi ini menyebabkan sendi-sendi terasa sakit, kaku, dan bengkak. ${ }^{1}$

Penyakit ini bisa menyerang semua sendi, namun sendi lutut, pinggul, dan tulang punggung, adalah sendi-sendi yang paling sering terkena. Gejala yang timbul saat mengalami osteoarthritis akan berkembang secara perlahan. ${ }^{1}$

Osteoartritis (OA) adalah gangguan sendi yang paling umum di Amerika Serikat. Jumlah orang yang terkena OA kemungkinan besar akan meningkat karena penuaan populasi dan obesitas. Di antara orang dewasa berusia 60 tahun atau lebih, prevalensi gejala OA lutut sekitar $10 \%$ pada pria dan $13 \%$ pada wanita. Sementara di Indonesia prevalensi osteoartritis lutut masih cukup tinggi yaitu $15,5 \%$ pada laki-laki dan $12,7 \%$ pada perempuan. ${ }^{2,3}$

Karena sifatnya yang kronis dan progresif, dampak sosial ekonomi di banyak negara maju dan berkembang sangat besar. Penyakit ini menyebabkan nyeri hebat dan kecacatan pada penderita, sehingga mengganggu aktivitas seharihari. Akibatnya, sebanyak $80 \%$ mengalami keterbatasan dalam beraktivitas dan $25 \%$ diantaranya bahkan tidak dapat melakukan aktivitas sehari-hari. ${ }^{3}$

Terdapat beberapa faktor resiko yang mempengaruhi terjadinya osteoarthritis. Secara garis besar faktor resiko tersebut di bagi menjadi 2, faktor resiko yang dapat dimodifikasi dan faktor resiko yang tidak dapat dimodifikasi. Faktor-faktor Nama Sub tema Penelitian 
resiko yang dapat dimodifikasi meliputi: riwayar trauma pada lutut, riwayat pekerjaan (kebiasaan bekerja dengan beban > 17,5 kg; Pekerjaan yang membutuhkan gerakan menekuk lutut repetitif; dll.), kebiasaan aktivitas fisik berat, obesitas, dan kelemahan otot. Sedangkan faktor-faktor yang tidak dapat dimodifikasi meliputi: jenis kelamin, usia, ras, dan genetik. ${ }^{4,5}$

Dari riwayat perjalanan penyakitnya, Osteoarthritis dapat terjadi akibat dari cedera atau penggunaan sendi lutut repetitif secara berlebihan. Nyeri biasanya adalah gejala utama dari Osteoarthritis. Hal ini disebabkan oleh perubahan struktural dalam sendi, mikrofraktur tulang, dan intra artikular hipertensi akibat pembengkakan, hipertrofi synovial, dan menyertai sinovitis. ${ }^{6}$

Kekakuan sendi yang dihasilkan dari proses inflamasi ringan biasanya terjadi pada pagi hari dan berlangsung kurang dari 30 menit. Krepitasi berbagai gerakan terbatas, dan deformitas terjadi dari hasil pembentukan osteofit, remodeling tulang dan kehilangan tulang rawan. Sedangkan fungsi osteofit adalah untuk mendukung dan menstabilkan sendi, namun dapat juga menghasilkan rasa nyeri, krepitasi, dan penurunan lingkup gerak sendi. Seiring dengan krepitasi maka akan ada deformitas. Efusi dan peradangan tidak terlihat di Osteoarthritis. ${ }^{6}$

Terjadinya Osteoarthritis tergantung interaksi antara beberapa faktor. Osteoarthritis dapat terjadi dari faktor usia lanjut, genetik, trauma, dan beban sendi karena obesitas. Banyak bukti bahwa obesitas merupakan sindrom kompleks dimana aktivitas abnormal neuroendokrin dan jalur proinflamasi berubah dari asupan makanan, Ekspansi lemak dan perubahan metabolik. Namun, leptin dapat juga diproduksi oleh osteoblas dan sel kondrosit. Tingkat signifikan, leptin yang diamati pada tulang rawan dan osteofit pada penderita Oseoarthritis sedangkan beberapa kondrosit diproduksi leptin dalam tulang rawan dari orang sehat. Leptin ditemukan dalam cairan synovial sendi Osteoarthritis yang berkolerasi. Sitokin, faktor biomekanika, dan enzim proteolitik menyebabkan derajat variable proses inflamasi synovial yang diatur oleh metalloproteinase dan kondrosit jalur sintesis kompensasi yang diperlukan untuk mengembalikan interitas matriks yang terdegradasi. ${ }^{6}$
Kriteria diagnosis dari OA lutut berdasarkan American College of Rheumatology yaitu adanya nyeri pada lutut dan pada foto rontgen ditemukan adanya gambaran osteofitserta sekurang kurangnya satu dari usia > 50 tahun, kaku sendi pada pagi hari $<30$ menit dan adanya krepitasi. ${ }^{7}$

Nyeri pada sendi tersebut biasanya merupakan keluhan utama yang membuat pasien datang ke dokter. Nyeri biasanya bertambah berat dengan gerakan dan berkurang dengan istirahat. Pada umumnya pasien OA mengatakan bahwa keluhannya sudah berlangsung lama tetapi berkembang secara perlahan. Daerah predileksi OA biasanya mengenai sendi-sendi penyangga tubuh seperti di pada lutut. ${ }^{7}$

Adapun gambaran radiologis sendi yang menyokong diagnosis OA adalah:

1.) Penyempitan celah sendi yang seringkali asimetris.

2.) Peningkatan densitas (sclerosis) tulang subkondral

3.) Kista tulang

4.) Osteofit

5.) Perubahan struktur anatomi sendi ${ }^{7}$

Strategi penatalaksanaan pasien dan pilihan jenis pengobatan ditentukan oleh letak sendi yang mengalami OA, sesuai dengan karakteristik masingmasing serta kebutuhannya. Oleh karena itu diperlukan penilaian yang cermat pada sendi dan pasiennya secara keseluruhan, agar terapinya aman, sederhana, memperhatikan edukasi pasien serta melakukan pendekatan multidisiplin. ${ }^{8}$

Tujuan dari tatalaksana osteoarthritis adalah:

1.) Mengurangi/mengendalikan nyeri.

2.) Mengoptimalkan fungsi gerak sendi.

3.) Mengurangi keterbatasan aktivitas fisik sehari hari (ketergantungan kepada orang lain) dan meningkatkan kualitas hidup.

4.) Menghambat progresivitas penyakit.

5.) Mencegah terjadinya komplikasi.

Terapinya meliputi nonoperasi dan operasi. Terapi nonoperasi meliputi: modifikasi gaya hidup, pemberian obat-obatan antinyeri (asetaminofen untuk nyeri ringan; NSID untuk nyeri sedang; dan opioat untuk nyeri berat), rehabilitasi, edukasi, aktifitas fisik, dan menjaga berat badan ideal. Terapi operasi meliputi osteotomi tibia dan penggantian sendi lutut. ${ }^{4,9}$

$$
\text { Nama Sub tema Penelitian }
$$


Prognosis osteoarthritis (OA) dapat baik apabila penyakit dapat ditemukan pada tahap kerusakan yang dini. Sampai saat ini belum ditemukan penatalaksanaan yang dapat menyembuhkan osteoarthritis secara definitif, dan penyakit ini sering menimbulkan hendaya pada aktifitas sehari-hari. Komplikasi yang dapat terjadi pada OA antara lain adalah: Penurunan kualitas hidup karena adanya hambatan dalam melakukan aktivitas sehari-hari akibat nyeri dan peradangan, gastropati AINS (gastritis dan gastroesofageal reflux disease (GERD)), nefropati AINS, fusi sendi akibat artrosentesi atau injeksi intra-artikular, dan stenosis spinal. ${ }^{10}$

\section{METODE}

Metode yang digunakan untuk pemecahan masalah dalam kegiatan ini adalah penyuluhan, simulasi yang dilanjutkan dengan diskusi. Materi penyuluhan yang diberikan mengenai osteoarthritis adalah:

1.) Definisi penyakit osteoarthritis

2.) Prevalensi dan epidemiologi osteoarthritis

3.) Faktor resiko osteoarthritis

4.) Patofisiologi osteoarthritis

5.) Gejala klinis dan pemeriksaan osteoarthritis

6.) Penatalaksanaan osteoarthritis

7.) Prognosis osteoarthritis

8.) Komplikasi osteoarthritis

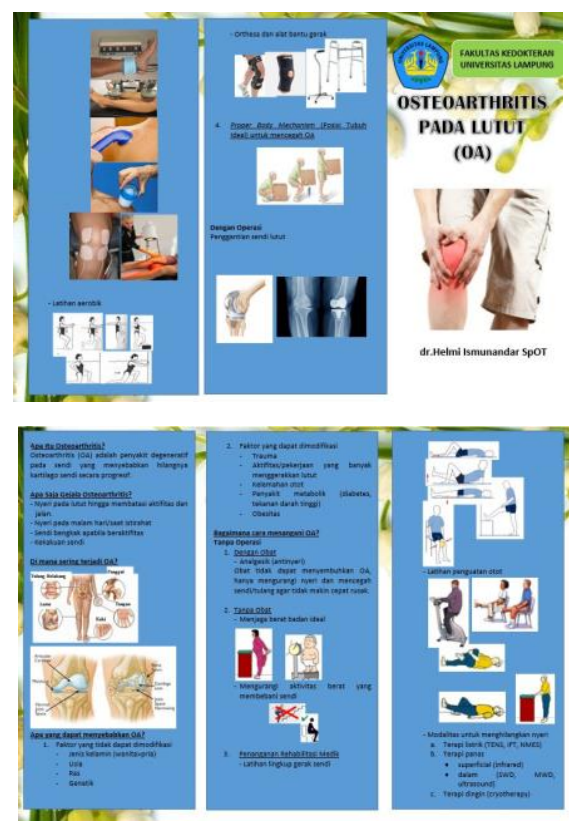

Gambar 1 Brosur Pengabdian

\section{HASIL DAN PEMBAHASAN}

Kegiatan Penyuluhan dilaksanakan pada tanggal 16 Oktober 2019 pada masyarakat Desa Branti Raya Lampung Selatan. Kegiatan dilaksanakan selama 2 jam (Pukul 09.00 s.d 11.00 WIB) dan dihadiri oleh 70 peserta yang datang. Sebelum dilakukan acara penyuluhan kesehatan, peserta mengisi daftar kegiatan dan dilakukan pembagian lembar kuisioner kepada peserta.

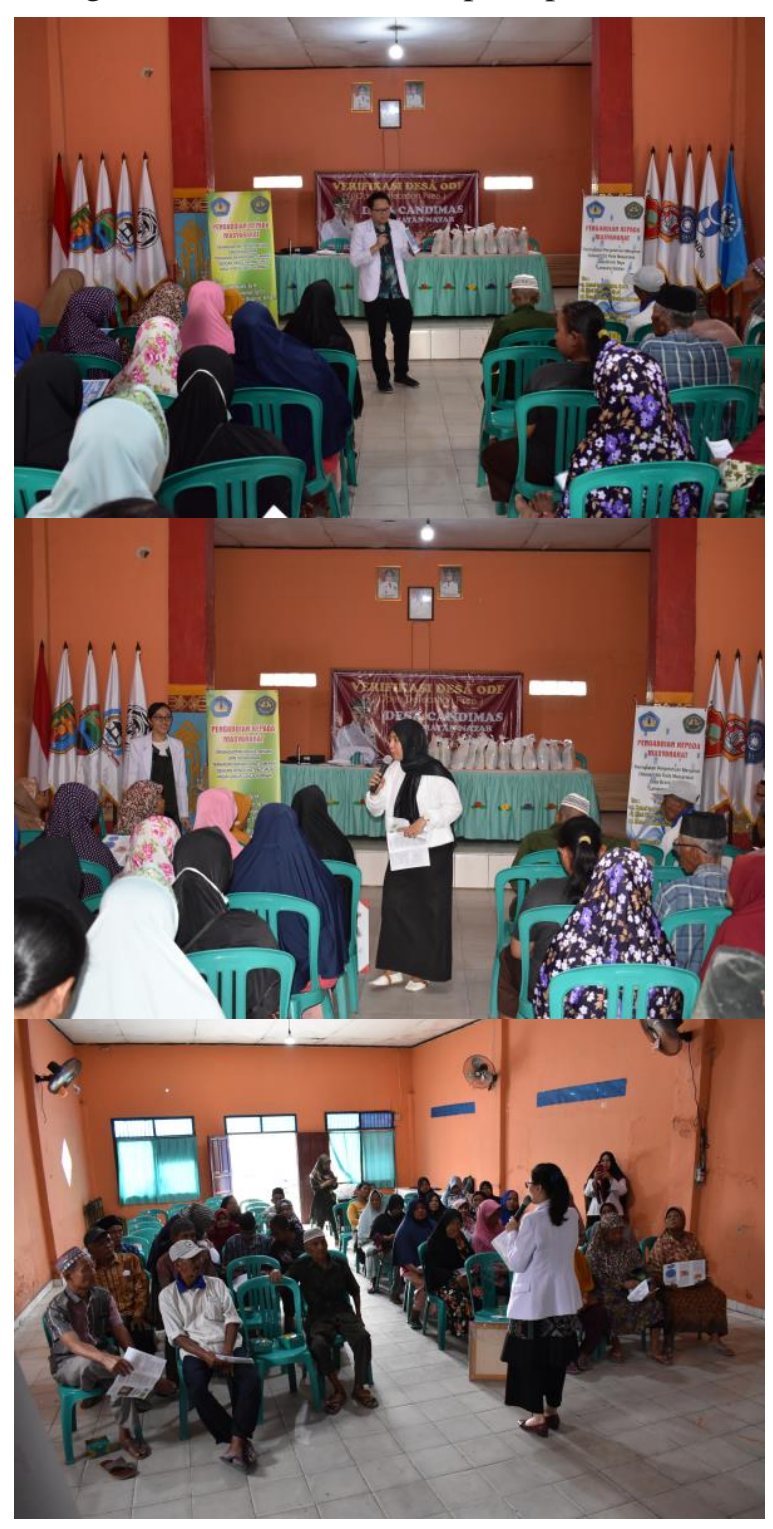

Gambar 2 Kegiatan Pengabdian

Kuisioner berisi pertanyaan-pertanyaan mengenai materi yang akan diberikan. Kegiatan ini dengan penyampaian materi, ada 3 orang dosen dari

Nama Sub tema Penelitian 
Fakultas Kedokteran Universitas Lampung yang hadir. Pemberi penyuluhan, antara lain definisi, prevalensi, dan faktor resiko osteoarthritis oleh dr. Helmi Ismunandar, SpOT; patofisiologi, gejala, dan penatalaksanaan osteoarthritis oleh dr. Rani Himayani, Sp.M; prognosis dan komplikasi osteoarthritis oleh dr. Rasmi Zakiah Oktarlina, M.Farm. Selama penyampaian materi oleh narasumber, peserta menyimak dengan tekun dan antusiasme yang tinggi. Setelah 3 orang narasumber selesai menyampaikan materi yang dibuka, forum tanya jawab mengenai materi yang telah disampaikan, kemudian evaluasi dilakukan dengan memberikan post-test kepada peserta yang berisi pertanyaan-pertanyaan yang sama yang telah diberikan pada pre-test.

Berdasarkan data hasil pengamatan pre-test, diketahui sekitar $60 \%$ peserta tidak paham mengenai pengetahuan mengenai osteoarthritis dan $40 \%$ telah mengetahui pengetahuan yang cukup mengenai pengetahuan penyakit ini. Setelah dilakukan kegiatan penyuluhan, nilai hasil pengamatan meningkat, peserta menjadi paham mengenai penyakit osteoarthritis. Setelah dilakukan post-test, dari data yang diperoleh semua peserta sudah paham $(100 \%)$ terhadap penyakit tersebut. Hal ini menunjukkan adanya peningkatan pengetahuan dan pemahaman.

Setelah mendapatkan penyuluhan mengenai osteoarthritis terdapat peningkatan pengetahuan masyarakat Desa Branti Raya Lampung Selatan. Diharapkan pengetahuan ini dapat bermanfaat untuk melakukan deteksi dini dan penatalaksaaan osteoarthritis yang baik pada diri sendiri maupun kepada keluarga dan masyarakat.

\section{KESIMPULAN}

Ada peningkatan pengetahuan mengenai osteoarthritis pada masyarakat Desa Branti Raya Lampung Selatan.

\section{REFERENSI}

1. Merry DC. (2020). Osteoarthritis. https://www.alodokter.com/osteoarthritis.

2. Joanne MJ. (2010). Epidemiology of Osteoarthritis. Clin Geriatr Med, 26(3): 355369

3. Ilham WA, Lita DR, Teddy HW. (2018). Demographic Profile, Clinical and Analysis of Osteoarthritis Patients in Surabaya. Biomolecular and Health Science Journal, 1(1): 34-39

4. Evan W and Mark K. (2020). Knee Osteoarthritis. https://bit.ly/33KQQhJ

5. Eka PM. (2010). Faktor-Faktor Resiko Osteoarthritis Lutut (Tesis). Universitas Diponegoro, Semarang.

6. Aditya DP. (2019). Intervensi Fisioterapi pada Kasus Osteoarthritis Genu di RSPAD Gatot Subroto. Jurnal Sosial Humaniora Terapan, 1(2): 21-34

7. Anisa IP. (2015). Diagnosis and Treatment Osteoarthritis. J Majority, 4(4): 10-17

8. Perhimpunan Rheumatologi Indonesia. (2014). Diagnosis dan Penatalaksanaan Osteoarthritis. Jakarta: PAPDI

9. Kentaro O, Amol U, Eric C. (2012). Osteoarthritis: A Critical Review. Crit Rev Phys Rehabil Med, 24(3-4): 1-12

10. Josephine J. (2020). Osteoarhtritis. https://bit.ly/2FDg21T 